\title{
Formação territorial do município de Rubiataba (GO): colônia agrícola, rede urbana e atividade sucroalcooleira (1950-2012).
}

\author{
Territorial formation of Rubiataba county $(G O)$ : \\ agricultural colony, urban network and sugarcane activity
} (1950-2012).

Formación territorial del municipio de rubiataba $(G O)$ : colonia agrícola, red urbana y actividad sucroalcoholera (1950-2012).

Leonardo de Castro Araújo

Universidade Federal de Goiás

Leo.dcastro.geo@gmail.com

\section{Resumo}

$\mathrm{O}$ presente trabalho analisa a formação territorial de Rubiataba e alguns elementos basilares da dinâmica socioespacial do município e região. A metodologia do trabalho foi baseada em pesquisa bibliográfica e documental, trabalho de campo, levantamento de dados em órgãos oficiais e em estabelecimentos comerciais e industriais do município. O trabalho analisa três questões fundamentais: o projeto de criação da colônia agrícola estadual, a atividade sucroalcooleira e a rede urbana. Assim dito, esperamos com esse trabalho contribuir para a interpretação da dinâmica territorial de Rubiataba e, consequentemente, da porção central de Goiás.

Palavras-chave: Rubiataba; Colônia Agrícola Estadual; Rede Urbana; Atividade Sucroalcooleira.

\footnotetext{
Abstract

This paper analyzes the territorial formation of the city of Rubiataba as well as some basic elements of the socio-spatial dynamics of the city and region. The methodology used for this study was based on literature review and documents analysis, fieldwork, data collection in official agencies and in business and
} 
industrial companies of the city. The paper analyzes three key issues: the project draft of creation of the state agricultural colony, the sugar and ethanol sectors, and the urban network. Therefore, this paper expects to contribute to the understanding of Rubiataba's territorial dynamics and, consequently, of the central region of Goiás state.

Keywords: Rubiataba. Agricultural Center. Urban Network. Sugar and Ethanol Sectors.

\begin{abstract}
Resumen
En este trabajo se analiza la formación territorial de Rubiataba y algunos elementos básicos de la dinámica socio-espacial de la ciudad y la región. La metodología del estudio se basa en la investigación bibliográfica y documental, trabajo de campo, recopilación de datos de los organismos oficiales y establecimientos comerciales y industrias de la ciudad. El artículo analiza tres cuestiones clave: el proyecto de la creación de la colonia agrícola del estado, la red urbana y la actividad sucroacoholera. Com todo esto, esperamos que este trabajo contribuya a la interpretación de la dinámica de Rubiataba y por lo tanto de la parte central de Goiás.
\end{abstract}

Palabras-clave: Rubiataba; Colonia Agrícola Estatal; Red Urbana; Actividad Sucroalcoholera.

\title{
Introdução
}

É curioso observar que no estado de Goiás foram muitos os projetos governamentais de criação de novas cidades. Tais projetos calcados em discursos modernistas e desenvolvimentistas prometiam sempre uma forte mudança na dinâmica socioespacial tanto no âmbito regional como nacional. É o caso, por exemplo, de Ceres, Goiânia e Brasília, cada qual calcados em contextos históricos diferentes e com pretensões específicas. Neste trabalho evidenciaremos a realidade territorial de Rubiataba, município goiano fundado a partir do projeto da colônia agrícola estadual, implantado no Vale de São Patrício.

Portanto o objetivo do trabalho é analisar a formação territorial de Rubiataba, ou seja, investigar a trajetória socioespacial do município a fim de compreender a atual dinâmica territorial. Dessa forma será levantado elementos do "ontem" e do "hoje" que combinado compõe uma trama que nos permite interpretar a atual dinâmica do município. Para isso, a estrutura do trabalho foi organizado em três partes, sendo que a primeira diz respeito a criação da colônia agrícola estadual e a formação do município de Rubiataba, a segunda aborda a rede urbana regional destacando a atividade moveleira e a oferta de bens e serviços, e por fim, a terceira parte evidência a atividade sucroalcooleira que ressurge na última década com muita força. Parte dos dados e das informações utilizadas na elaboração do presente trabalho foi resultado de trabalho de campo (28-10-11) realizado na cidade que contou com vizitas 
técnicas e com aplicação de questionários nas indústrias de moveis, no comércio local e na CoperRubi.

De forma geral, esses três pontos tratados em conjuntos oferecem uma boa "imagem" da formação e da dinâmica territorial do município. Espera-se também contribuir para a análise das cidades pequenas no estado de Goiás, muitas vezes desprestigiados equivocadamente pela pesquisa acadêmica.

\section{A criação da colônia agrícola estadual e a formação territorial do município de Rubiataba.}

O município de Rubiataba-GO possui uma área territorial de 748,27 $\mathrm{km}^{2}$ (SEGPLAN, 2012) e está localizado na microrregião de Ceres (Figura 01). A população total do município é de 18.848 habitantes (Censo2010) em sua maioria urbana (85.73\%). Assim como os demais municípios da microrregião de Ceres, apresenta taxas de crescimento demográficas muito baixas. O município de Rubiataba faz limite com Ceres, Ipiranga de Goiás, Itapaci, Morro Agudo de Goiás, Nova América, Nova Glória e São Patrício. Apresenta relevo plano e abundância no que confere aos recursos hídricos, com destaque aos rios São Patrício e Rio Novo.

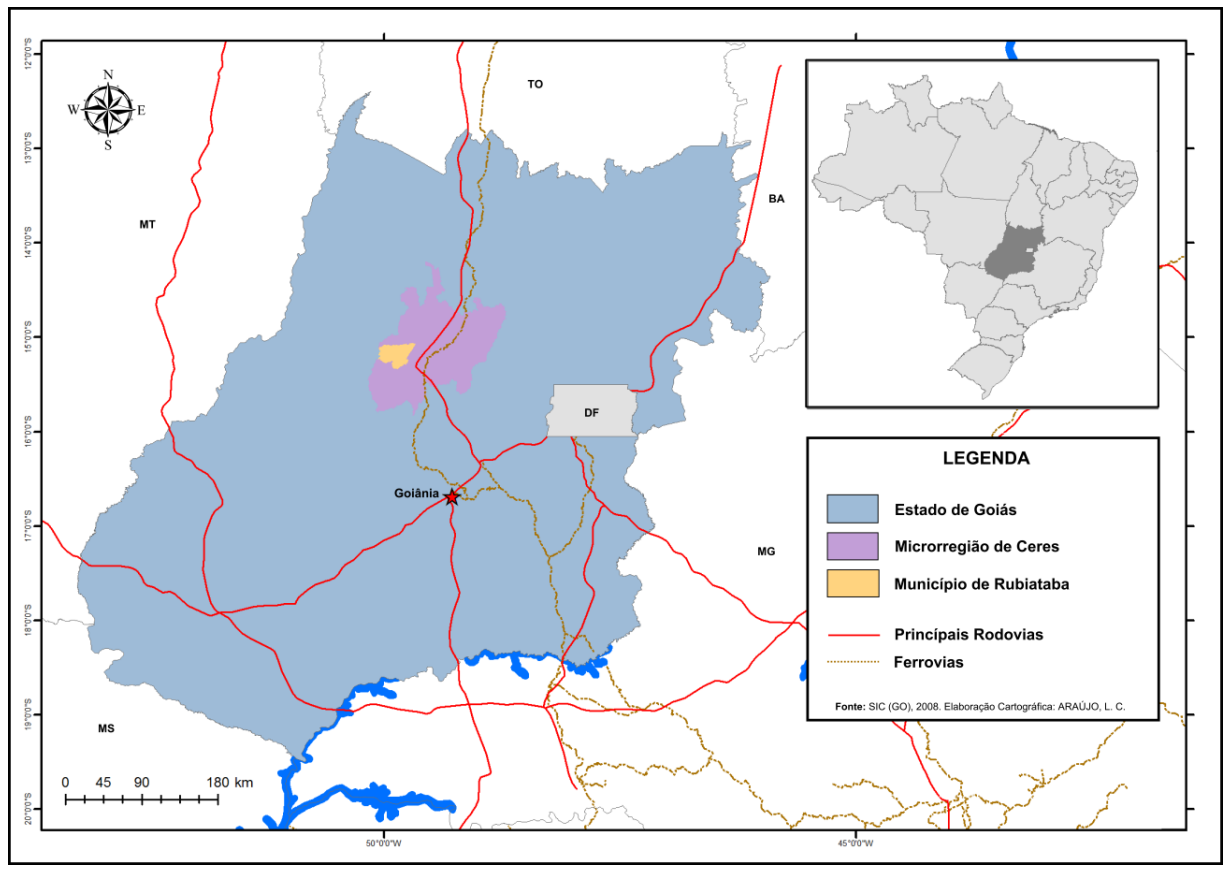

Figura 01: Mapa de localização de Rubiataba no Estado de Goiás. 
A formação territorial de Rubiataba está condicionada a um contexto histórico desenrolado na primeira metade do séc. XX, no qual o governo brasileiro vislumbrava a necessidade de ocupar e tornar produtivo a região central do país, ainda pouco explorada. No governo Vargas surge políticas voltadas para esse fim, das quais culminam na chamada "marcha para o oeste" cuja iniciativa visava promover a ocupação do "grande vão" do território brasileiro. Surgiram então as Colônias Agrícolas Nacionais que tinham essencialmente esse objetivo.

Para a ocupação do Planalto Central foi implantada a Colônia Agrícola Nacional de Goiás (CANG) em 1941, localizada em terreno fértil e rico em recursos hídricos na antiga região "Matogrosso Goiano". Em 1943 foi criado o distrito de Ceres vinculado ao município de Goiás. Mais tarde em 1953, o distrito foi elevado à categoria de município com a denominação de Ceres.

O governo do Estado de Goiás, motivado pelo projeto da CANG, decide estabelecer uma colônia estadual no Vale do São Patrício inspirado no modelo aplicado pelo governo federal. Para Paula, Silva e Cordeiro (2007, p.736) o governador do Estado de Goiás, Coimbra Bueno (1947-1950), "percebeu a importância de iniciativas que buscassem acelerar e garantir a implantação da futura capital federal no Planalto Central".

Dessa forma, baseado na estratégia de agrovilas, o governo de Goiás cria o projeto do núcleo populacional de Rubiataba em 1949. Em 1950, iniciose a planificação da colônia agrícola em uma área de 150.000 há de terras que foram divididas em 3.000 quinhões de 10 alqueires goianos que em seguida, foram doados aos agricultores vindos de várias partes do país (ENCICLOPÉDIA DOS MUNICÍPIOS BRASILEIROS, 1958, p. 190). O planejamento e a execução do projeto foi idealizado pelo engenheiro agrônomo Oscar Campus Junior diretor da Divisão de Terras e Colonização da Secretaria da Agricultura do Governo de Goiás (PAULA; SILVA; CORDEIRO, idem, p. 738). O que chamou a atenção na formação de Rubiataba foi o rápido crescimento populacional que o núcleo agrícola registrou em sua fase inicial, sendo que em 1951 o povoado de Rubiataba já contava com 20.000 habitantes.

Este forte crescimento populacional contribuiu para que em 1953 o povoado fosse elevado à categoria de município por meio da Lei Estadual $n^{\circ}$ 807, tendo como distrito sede o ex-povoado de Rubiataba. O nome do município (Rubiataba = "rubiácea" e "taba") faz referência a um antigo cafezal localizado na região que representou a principal atividade agrícola-econômica do município na sua fase inicial. No planejamento da cidade, as ruas receberam nomes de frutas e madeiras em homenagem a natureza. Desde sua formação, a base da produção agrícola de Rubiataba sempre foi pouco diversificada, apresentando principalmente a produção de café, milho, arroz e feijão. 
Em meados da década de 1970 um fato chama a atenção no desenvolvimento demográfico de Rubiataba: a diminuição quantitativa da população total e a inversão da população rural para urbana. No gráfico 01 pode-se observar que os dados indicam que a partir da década de 1970 a população total do município de Rubiataba decai até a década de 1990 quando estagna, apresentando taxas de crescimento muito baixas presentes até o atual momento. Cabe ressaltar que a população total do município de Rubiataba contabilizada em 2010 é inferior a população do município em 1970.

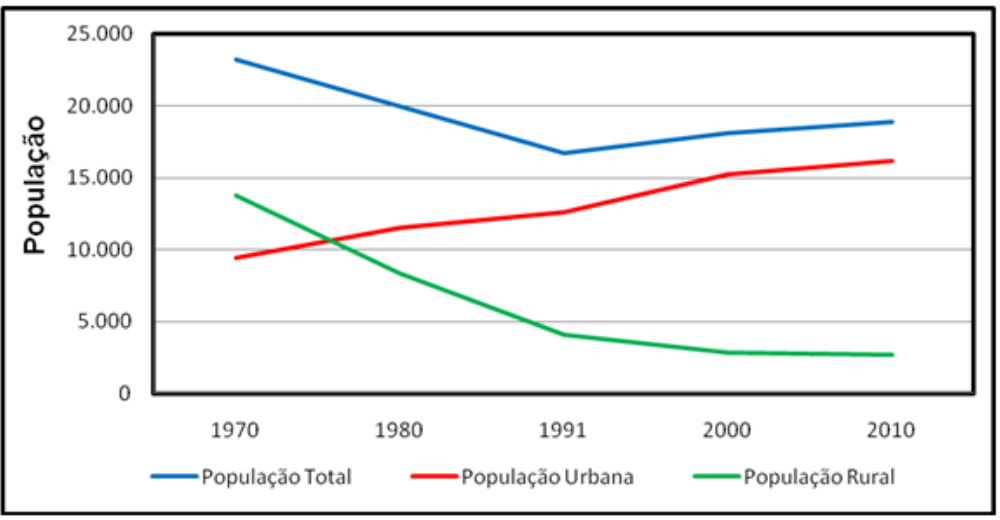

Gráfico 01 - Evolução populacional do município de Rubiataba-GO (1970-2010).

Fonte: Instituto Brasileiro de Geografia e Estatística - IBGE (1970-2010).

A gênese do desenvolvimento do município de Rubiataba está centrada em um projeto rural que tem como fundamento a ideia de colônia agrícola, o que justifica a população rural ser maior do que a população urbana na sua fase inicial. A partir da década de 1970, o município vai experimentar a inversão da população urbana sobre a rural por meio do crescimento da população urbana e do declínio da população rural. Nota-se que a população urbana sempre apresentou crescimento contínuo e que a população rural apresentou significativo declínio nas décadas de 1970 e 1980. Esse fato demonstra que a perda de população total do Município de Rubiataba está relacionada à perda da população rural.

Esta questão coloca em evidência o fracasso do projeto agrícola do município de Rubiataba, uma vez que a estagnação populacional acompanhou também a estagnação econômica. A perda da população rural aponta a ineficácia do projeto agrícola pleiteado pela colônia agrícola estadual que representaria para a região uma atividade de "impulso econômico". 


\section{Rubiataba e a rede urbana: produção, apropriação e circulação de capital}

Para Corrêa (1994) é por meio da rede urbana que se dá a produção, a apropriação e a circulação de valor excedente. Essa realidade pressupõe que existam empresas, indústrias, trabalho, mercadorias, ideias, capital, comércio, vias, interesses, etc. em um sistema único e integrado. As cidades emergem nesse sistema enquanto centros de gestão do território, onde se verificam os processos de tomada de decisões e a localização de espaços funcionais destinados ao comércio varejista, as transformações industriais, a prestação de serviços, a concentração do poder público, etc. Para Fresca (2010, p. 119) é por meio da rede urbana que os centros urbanos de diferentes tamanhos e funções realizam diferentes atividades e interações espaciais que envolvem a distribuição do comércio varejista e a prestação de serviços, expressando, dessa forma, o nível de desenvolvimento da divisão social ou territorial do trabalho. Nessa perspectiva, qual a função de Rubiataba na divisão territorial do trabalho? Qual a sua participação na distribuição ou na procura do comércio varejista ou na oferta de serviços? Como se dá a produção, a apropriação e a circulação de valor excedente socialmente produzido? Enfim, como se configura a rede urbana em Rubiataba? Portanto, será apresentada uma breve análise da dinâmica socioespacial da atividade moveleira e da centralidade terciária que são fundamentais para se compreender a rede urbana de Rubiataba.

Começamos nosso itinerário com a atividade moveleira. Os principais municípios produtores de móveis no Estado de Goiás são Goiânia, Anápolis, Aparecida de Goiânia, Inhumas e Rubiataba. Segundo dados do SEPLAN (2007) essa atividade é responsável pela geração de 10.000 empregos diretos e uma movimentação financeira de R \$ 25 milhões mensais no Estado. É característica desse setor a atuação por meio de micro e pequenas empresas, o que é interessante do ponto de vista da geração de empregos e da distribuição da renda.

Segundo Paula, Silva e Cordeiro (2007, p. 750) em 2007 a produção de móveis anuais totalizou cerca de 31.000 peças com um total de 45 unidades o que representa $45,98 \%$ do total de estabelecimentos industriais do município naquele ano.

Em pesquisa de campo ${ }^{1}$ realizado na cidade de Rubiataba foi visitado duas indústrias de móveis. Na primeira, Móveis Lugui, o proprietário informou que os principais destinos das mercadorias estão no próprio Estado de Goiás, em Brasília e no Pará. A empresa emprega 26 funcionários e a média salarial é de um salário e meio. Além disso, a indústria trabalha de forma indireta com

\footnotetext{
${ }^{1}$ Trabalho de campo realizado em 28-10-11.
} 
outras 12 marcenaria que se cooperam para aquisição de matéria-prima mais barata. A segunda empresa visitada, Estofados Solar, é maior no ramo de estofados em Rubiataba. A indústria gera 150 empregos diretos e 30 indiretos e a faixa salarial é de 01 a 03 salários mínimos. A empresa possui aproximadamente novecentos 900 clientes em 10 Estados brasileiros.

Por tanto, a atividade moveleira em Rubiataba abrange varias localidades em escala nacional, mesmo por se tratar de pequenas e médias indústrias de uma cidade pequena. Esse fato pode ser explicado pela especialização produtiva - móveis melhor trabalhados - que contribuem para a formação de um "selo" de qualidade local e pela organização em rede. Sobre as redes geográficas, Corrêa $(2010$, p. 107) as define como "um conjunto de localizações geográficas interconectadas entre si por um certo número de ligações" que possuem características e finalidades próprias. É por meio das redes de produção, circulação e apropriação que as corporações efetivam o lucro.

A título de exemplificação, a rede da Estofados Solar é constituída pelo elo entre sede, fábrica e depósito (uma única localização) e as filiais de venda distribuídas em varias cidades que são comercializadas as mercadorias. É por meio de redes que a atividade moveleira de Rubiataba se realiza uma vez que o comercio local não é suficiente para manutenção de uma atividade de consumo deste porte, como acontece, por exemplo, na região metropolitana.

No que se refere a Rubiataba, as empresas moveleiras são importantes para a geração de empregos - o que contribui para que a população não necessite migrar para outras cidades - e para a fixação de capital na cidade. Existe um grande potencial desse setor em Rubiataba, porém ainda prevalece desorganização e pouca cooperação do setor.

Além da atividade moveleira, uma outra questão se faz importante para compreender a rede urbana de Rubiataba. Trata-se da formação de uma área de influência local dada pela oferta de bens e serviços. Esta centralidade terciária possui uma dimensão espacial bem definida pelas avenidas Jatobá (Figura 02) e Aroeira. Para Souza (2010, p. 64) "os espaços onde os bens mais sofisticados são produzidos (áreas industriais) ou comercializados (espaços comerciais) não estão totalmente dispersos no tecido urbano, mas, muito pelo contrário, tendem a se restringir a algumas áreas no interior da cidade". Ai se instala uma lógica espacial da proximidade e da otimização dos lucros. 


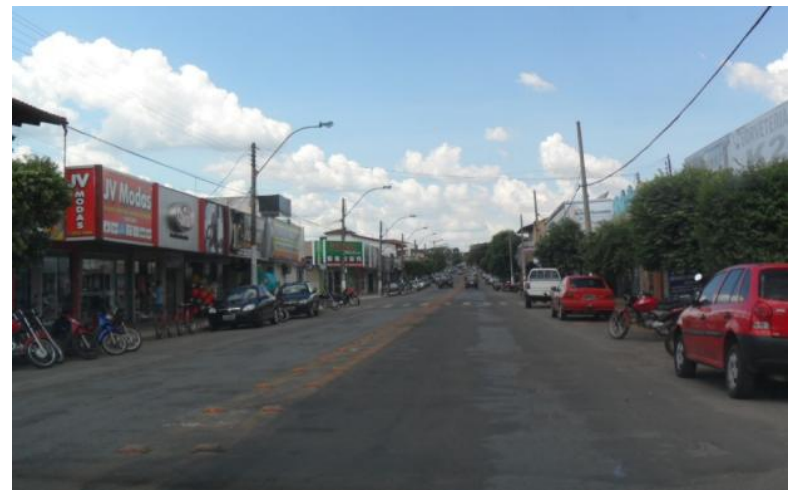

Figura 02: Avenida Jatobá - Rubiataba (GO)

Fonte: Araújo, L. C. (Trabalho de Campo, 2011).

No entanto a centralidade formada pelas Avenidas Jatobá e Aroeira não é fruto apenas da dinâmica do município de Rubiataba, mas envolve também a dinâmica socioespacial dos municípios do entorno. Há, do ponto de vista da centralidade, a localização de inúmeros "objetos urbanos" que favorecem a função polarizaste - mesmo que em escala pequena - de Rubiataba, como por exemplo a presença de agências de banco e dos Correios, oficinas mecânicas, lojas de produtos agropecuários, farmácias, depósitos de matérias de construção, mercados, lojas de eletrodomésticos, clínicas, etc.

Essa diferenciação do espaço intra-urbano e a evidência das avenidas Jatobá e Aroeira como a centralidade de Rubiataba, compactua com a ideia defendida por Amorim Filho (2005) de que a dinâmica regional interfere na organização dos espaços intra-urbanos, uma vez que a centralidade dessas avenidas é resultado justamente de uma trama de relações que envolvem a cidade e os municípios que compõe sua hinterlândia. Para Corrêa (2010, p. 123) "a emergência da Área Central de uma cidade é concomitante a ampliação das relações entre cidade e o mundo externo à ela, que se verifica a partir do advento da revolução industrial". Nessa perspectiva é importante salientar que o alcance da área central de uma cidade, no que confere ao comércio, pode extrapolar os próprios limites territoriais do município, e a dimensão da sua centralidade "é função, acima de tudo, de sua capacidade de ofertar bens e serviços para outros centros urbanos, estabelecendo desse modo, uma área de influência" (SOUZA, 2010, p. 57).

A tabela 01 destaca uma serie de informações socioeconômicas que contribuem para a compreensão da inserção de Rubiataba na rede urbana regional. Primeiramente, dentre os municípios listados abaixo, a população de Rubiataba é a segunda maior com 18.915 habitantes, possui um total de 597 
empresas registradas em 2008. Além disso, ainda possui 04 agências bancárias e 15 unidades de saúde, estabelecimentos que contribuem para os deslocamentos intermunicipais. Essas informações evidenciam uma grande discrepância de Rubiataba em relação aos demais municípios (com exceção a Ceres que é um centro de Zona A e está sendo utilizado como elemento de comparação), o que atesta para uma hierarquia funcional mais complexa e ampla em termos de dinâmica urbana.

Tabela 01: Dados socioeconômicos dos municípios que compõe a área Região de Influência de Rubiataba-GO.

\begin{tabular}{|l|c|c|c|c|}
\hline Municípios & $\begin{array}{c}\text { População Total } \\
\text { (2010) }\end{array}$ & $\begin{array}{c}\text { Numero de } \\
\text { empresas (2010) }\end{array}$ & $\begin{array}{c}\text { Bancos } \\
\text { (2012) }\end{array}$ & $\begin{array}{c}\text { Estabelecimentos } \\
\text { de saúde (2009) }\end{array}$ \\
\hline Carmo do Rio Verde & 8.928 & 199 & 2 & 6 \\
\hline Ceres & 20.722 & 838 & 4 & 2 \\
\hline Ipiranga de Goiás & 2.844 & 44 & 0 & 3 \\
\hline Morro Agudo de Goiás & 2.356 & 29 & 0 & 7 \\
\hline Nova América & 2.259 & 32 & 1 & 15 \\
\hline Nova Gloria & 8.508 & 214 & 4 & 1 \\
\hline Rubiataba & 18.915 & 597 & 0 & 2 \\
\hline São Patrício & 1.991 & 32 & $010 /$ Assistencia \\
\hline
\end{tabular}

Fonte: IBGE (Censo demográfico 2010/ Cadastro Central de Empresas, 2010/ Assistência Médica Sanitária, 2009). Associação de Bancos do Estado de Goiás.

Para investigar a formação e o alcance da área de influência de Rubiataba - no que tange ao comércio e aos serviços - utilizou-se de informações coletadas por meio de pesquisa em campo em estabelecimentos localizados das avenidas Jatobá e Aroeira. Procurou-se identificar a origem e a intensidade dos fluxos intermunicipais orientados para Rubiataba. Constatouse, portanto, que em maior grau de frequência há o deslocamento de pessoas de Ipiranga de Goiás, Nova Glória e Nova América. Em um grau menos frequente o município Morro Agudo de Goiás de São Patrício e em grau de pouco frequência os municípios de Itapaci e Carmo do Rio Verde. A atração que a cidade de Rubiataba exerce se destaca principalmente entre cidades locais baixa centralidade e densidade demográfica - que pertencem a sua hinterlândia. Estas informações se assemelham com os resultados apresentados pelo Regic (2007) que caracteriza a cidade de Rubiataba como Centro de Zona B. A figura 03 representa graficamente a área de influência de Rubiataba a partir dos dados coletados. 


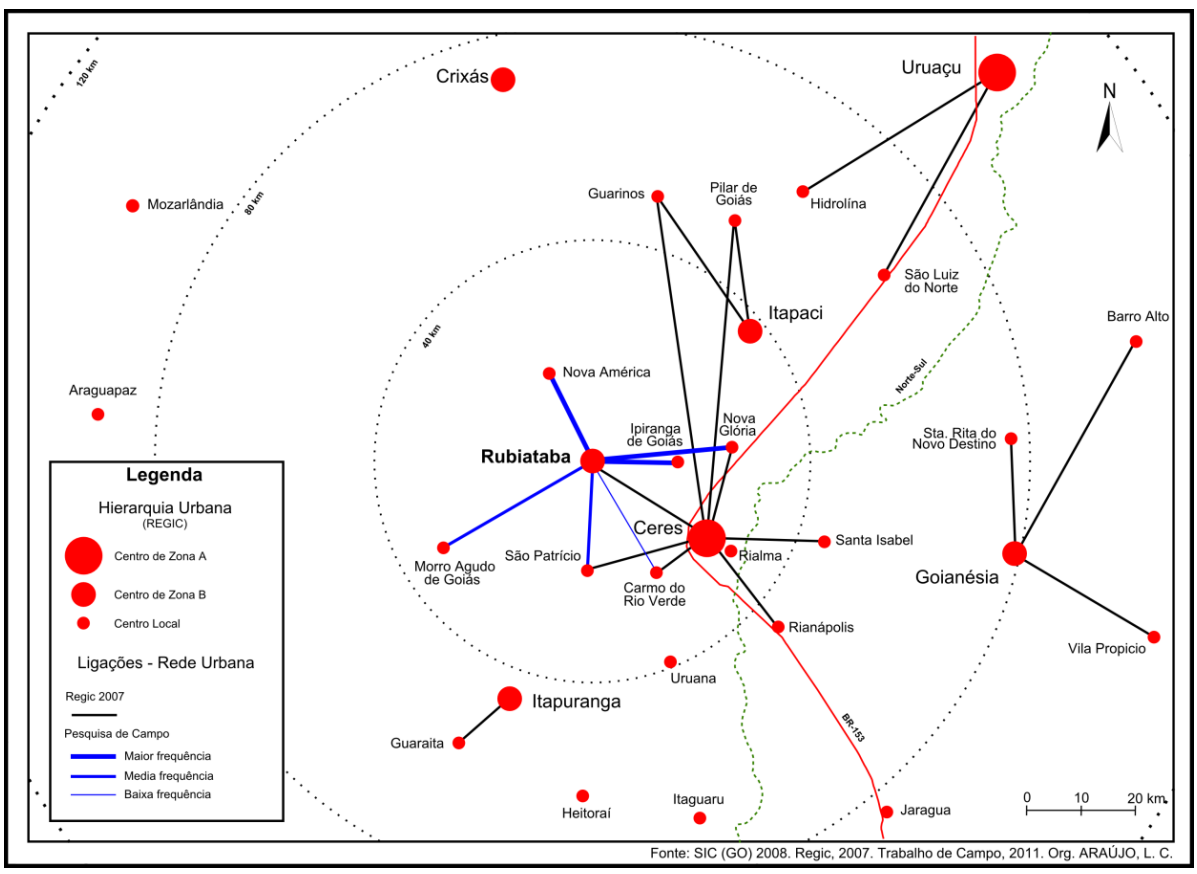

Figura 03: Área de influência de Rubiataba-GO.

Dentro do contexto regional é possível observar o adensamento de centros urbanos ao longo do traçado da BR-153, que em realidade é uma "importante via de urbanização". Nesta porção do território, em um raio de 50 km a partir de Rubiataba, a maior parte das cidades são constituídas por centros com menos de 10 mil habitantes. As cidades de Itapaci, Itapuranga, Rubiataba e Ceres se destacam como centros de zona. A força territorial de Rubiataba "esbarra" no protagonismo regional de Ceres, que apresenta níveis de centralidade e de especialização mais expressivas.

\section{Atividade sucroalcooleira}

A atividade sucroalcooleira está presente no Município de Rubiataba desde a década de 1980, com a implantação de uma cooperativa agroindustrial chamada Cooper-Rubi (1986) que inicialmente era representada por 62 cooperados locais. A criação desta cooperativa está relacionada com os incentivos públicos para a produção de etanol principalmente com a atuação do 
Programa Nacional do Álcool-Proálcool ${ }^{2}$ no qual tinha como fundamento promover a diversidade energética do Brasil - produção de etanol - frente às instabilidades internacionais da oferta e do preço do petróleo na década de 1970. Assim, a Cooperativa foi fundada por meio da parceria de lideres políticos, empresários e produtores locais.

$\mathrm{Na}$ década de 1990 a cooperativa, assim como o projeto do PROÁLCOOL, entra em crise e parte dos seus colaboradores abandonam o empreendimento diminuindo as atividades econômicas e produtivas. Na década seguinte, o setor sucroalcooleiro deslumbra novamente um novo crescimento, porém agora incentivado pelo discurso das "energias verdes" menos poluentes e danosas ao meio ambiente. Obviamente que os interesses são outros, mas tal política resultou em significativas mudanças no território brasileiro. Um fator de extrema relevância a esse cenário foi o desenvolvimento em larga escala dos carros bicombustíveis que dinamizaram e viabilizaram a expansão da atividade sucroalcooleira no país.

Este quadro é claramente perceptível em Rubiataba, principalmente no ano de 2003 quando um grupo tradicional do setor sucroalcooleiro da Paraíba Japungu - adquiriu $80 \%$ das ações da Cooper-Rubi. Esse grupo passa a ser acionista majoritário e o controle e a gestão da cooperativa deixa de ser local e desloca-se para uma outra sede em outro estado. Além da Cooper-Rubi, este mesmo grupo possui uma usina no município vizinho, Carmo do Rio Verde, e outras nos estados de Pernambuco e Paraíba.

Após a aquisição da Cooper-Rubi pela grupo Japungu verifica-se um expressivo crescimento das atividades sucroalcooleiras no município de Rubiataba. Esse crescimento pode ser identificado no aumento da área plantada de cana-de-açúcar e na produção total de álcool da usina. O gráfico 02 indica o percentual de área plantada das principais culturas do município de Rubiataba entre os anos de 1990 e 2010.

\footnotetext{
2 "O Programa Nacional do Álcool ou Proálcool foi criado em 14 de novembro de 1975 pelo decreto $\mathrm{n}^{\circ} 76.593$, com o objetivo de estimular a produção do álcool, visando o atendimento das necessidades do mercado interno e externo e da política de combustíveis automotivos. De acordo com o decreto, a produção do álcool oriundo da cana-de-açúcar, da mandioca ou de qualquer outro insumo deveria ser incentivada por meio da expansão da oferta de matérias-primas, com especial ênfase no aumento da produção agrícola, da modernização e ampliação das destilarias existentes e da instalação de novas unidades produtoras, anexas a usinas ou autônomas, e de unidades armazenadoras". Disponível em: http://www.biodieselbr.com/proalcool/pro-alcool.htm (Acessado em: 07/01/2012).
} 


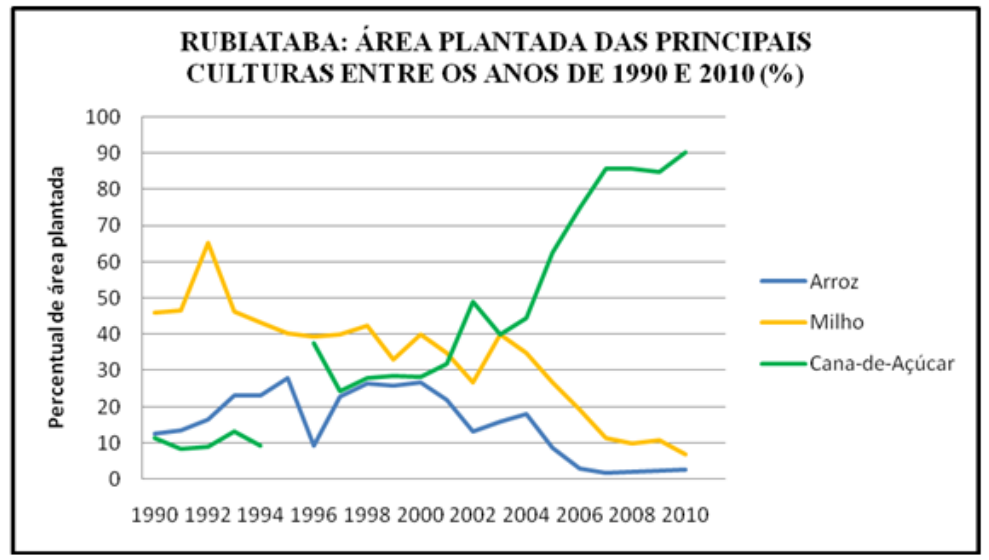

Gráfico 02 - Rubiataba-GO: Área plantada das principais culturas entre os anos de 1990 e 2010.

Fonte: IBGE - Produção Agrícola Municipal (1990-2010).

A produção de alimentos do município se vê comprometida pela conversão da produção ${ }^{3}$ que a atividade sucroalcooleira submete ao campo. Até a década de 1990, o milho era a principal cultura do município o que representava aproximadamente $45,99 \%$ do total da área plantada, seguida pelo arroz com $12,53 \%$ e da cana-de-açúcar com $11,4 \%$. Em meados da década de 1990 e inicio da década de 2000 esse quadro começa a mudar com a queda significativa da produção de milho e arroz, principalmente a partir de 2004, e o aumento da área plantada de cana-de-açúcar que apresenta um rápido crescimento também em 2004. Inicia-se a década de 2010 em uma situação completamente diferente e oposta a década de 1990: a produção de milho e arroz juntas representa apenas $9,63 \%$ do total de área plantada sendo que a produção de cana-de-açúcar representa 90,24\%.

Sobre a produção de álcool combustível, a Cooper-Rubi se destaca como a segunda maior produtora (safra 2006/07) na microrregião de Ceres, como enfatiza Ferreira e Deus (2011, p. 210). A partir da década de 2000 a produção de álcool apresenta significativo aumento como demonstra o gráfico 03.

\footnotetext{
3 A conversão da produção é dada pela substituição de uma cultura por outra em uma determinada região. Geralmente traduz o movimento de expansão de monoculturas como a soja e a cana-de-açúcar.
} 


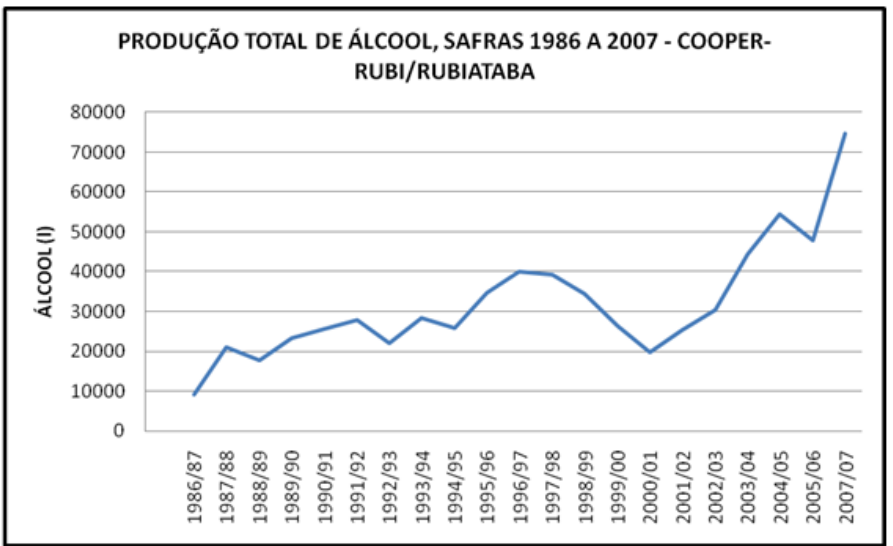

Gráfico 03 - Produção total de álcool, safras 1986 a 2007 Cooper-Rubi/Rubiataba

Fonte: Ferreira e Deus (2011, p. 210-211)/ Adaptado pelo autor.

Para fins organizacionais a empresa foi desmembrada em duas organizações: a Agrorubi, responsável pela produção, corte e transporte da cana-de-açúcar e a Cooper-Rubi responsável pela produção de álcool. A Cooper-Rubi emprega 306 funcionários diretos e a Agrorubi emprega na safra 1687 funcionários e na entressafra 1399 funcionários. Ao todo a empresa emprega um total de 1993 funcionários na safra e 1705 na entressafra. Segundo informações cedidas pelo economista da CooperRubi, a média salarial dos funcionários gira entorno de $\mathrm{R} \$ 1.150,00$ para os que trabalham no corte e $\mathrm{R} \$ 1.400,00$ a $\mathrm{R} \$ 1.500,00$ para os que trabalham no transporte. Porém, de acordo com o histórico da atividade sucroalcooleira no Brasil, esses dados são, no mínimo, duvidosos.

Toda a estrutura produtiva e tecnológica da Cooper-Rubi é voltada para a máxima produtividade possível (investir para produzir mais gastando menos): o corte mecanizado já foi aplicado aos canaviais da usina, o bagaço da cana-de-açúcar é reutilizado - queima do bagaço na geração de energia e a água utilizada na limpeza da matéria-prima é reaproveitada várias vezes. Atualmente, a empresa passa por uma ampliação do seu pátio industrial (Figura 05) que deverá capacitar a indústria a produzir açúcar nos próximos anos, aproveitando as oscilações do preço internacional do produto que atualmente representa um excelente negócio. 


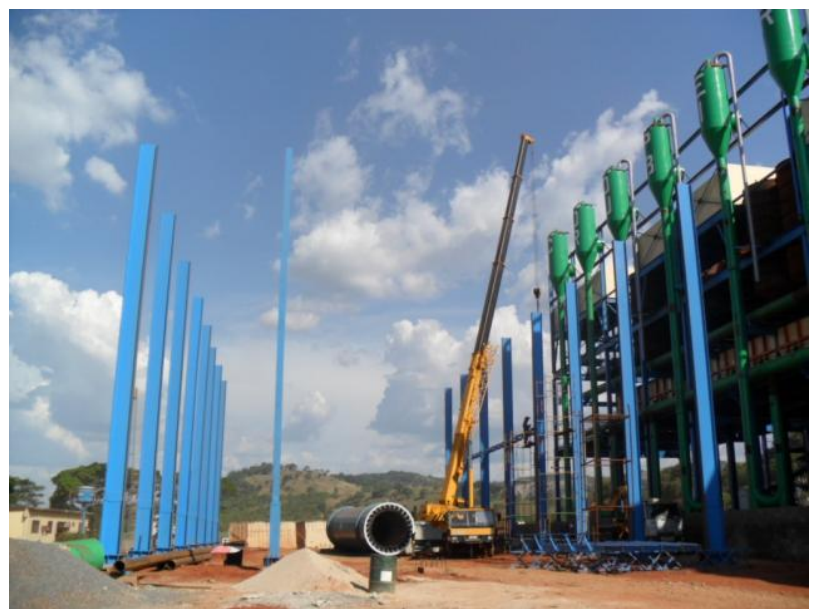

Figura 05 - Ampliação do pátio industrial da CooperRubi para a produção de açúcar.

Fonte: Araújo, L. C. Trabalho de campo (28/10/2011).

A maior parte dos trabalhadores são moradores de Rubiataba e dos municípios vizinhos. Há um "dizer popular" na cidade que diz que "quem mora em Rubiataba já trabalhou, trabalha ou ainda vai trabalhar na usina". Existe uma grande dependência do município com a indústria do álcool que emprega boa parte da população e que, de uma forma ou de outra, participa da circulação interna de capital por meio dos salários pagos.

A distribuição da produção da Cooper-Rubi abrange 07 estados brasileiros - Goiás, Bahia, Pará, Maranhão, Piauí, Ceará, Paraíba - de acordo com informações divulgadas pela própria empresa.

Cabe ressaltar o poder de transformação territorial que o Capital Sucroalcooleiro impõe aos territórios por meio dos seus empreendimentos. Trata-se do movimento-força de desterritorialização e territorialização (HAESBAERT, 2004) que implica em uma trama de transformações socioespaciais. No campo, as transformações são muito fortes, sendo a própria paisagem um meio que se evidencia com mais precisão as marcas da atividade sucroalcooleira. O Primeiro contato na entrada do município de Rubiataba é com o forte odor exalado pela vinhaça da usina e a extensão dos "intermináveis" canaviais. O processo de arrendamento de terras extrapola os limites do município de Rubiataba e vai até os municípios de Ipiranga de Goiás, Nova Glória, Rialma, Santa Isabel, Ceres, Carmo do Rio Verde e São Patrício (FERREIRA e DEUS, 2011, p. 213). O arrendamento de terras - 
instrumento eficaz na sistematização da monocultura da cana-de-açúcar rompe com as divisões entre as propriedades para melhor operacionalizar a atividade de produção e intensifica a migração campo-cidade.

Deste modo, percebe-se o poder e o controle exercido pela CooperRubi no município de Rubiataba. Há total prevalência da monocultura de canade-açúcar que substituiu outras culturas importantes. Grande parte dos trabalhadores e do capital que circula na cidade é oriunda das atividades da usina. Nesse quadro, a Cooper-Rubi controla boa parte da produção agrícola, da força de trabalho e dos salários pagos em Rubiataba e, consequentemente, o capital que circula no comércio local da cidade e sua capacidade de aumentar ou diminuir. Por fim, percebe-se que para a indústria sucroalcooleira as cidades são suporte e recurso técnico, logístico-operacional, político, ideológico e, sobretudo, humano.

\section{Considerações Finais}

A trajetória socioespacial do município de Rubiataba se inicia a partir da criação de uma colônia agrícola estadual no Vale de São Patrício. É interessante destacar a dupla iniciativa de criação de colônias agrícolas na região, a primeira promovida pelo governo federal que culminou na criação de Ceres, e a segunda por iniciativa do estado de Goiás com a criação de Rubiataba. Ao longo do tempo ambos os projetos vão se desfazendo, uma vez que a pura distribuição de terras não era suficiente para promover o desenvolvimento - social e econômico - almejado pelos governos. O movimento de ocupação da região foi promovido por famílias pobres, desprovidas de capital, com baixo poder de investimento. A produção e a "lida" com terra era essencialmente artesanal.

Posteriormente o município desenvolve outras atividades econômicas, muitas relacionadas com o aumento da população urbana. Dessa forma a cidade de Rubiataba passa a concentrar uma certa quantidade de estabelecimentos comerciais que atende a demanda do município e da região do seu entorno, constituída por cidades locais, com baixa centralidade. Destaca-se também o desenvolvimento de pequenas e médias indústrias moveleiras, que são importantes para a geração de empregos e para a fixação de renda no município.

A atividade sucroalcooleira retoma força em Rubiataba a partir da década de 2000. Essa atividade se destaca pelo poder de transformação territorial que se aplica aos municípios inseridos na sua lógica produtiva. Há por parte da atividade sucroalcooleira um grande consumo de espaço, de 
recursos naturais, de força de trabalho, além de tornar os municípios vulneráveis aos interesses políticos e econômicos dessas corporações.

É obvio que estes elementos não representam a totalidade do município de Rubiataba. No entanto, retratam os principais elementos envolvidos na "trama espacial" (GOMES, 2007) que compõe a formação e a dinâmica territorial do município. Deste modo, pretende-se contribuir para a análise da formação territorial dos municípios goianos, trazendo como referência, o caso de Rubiataba.

\section{Referências}

AMORIM FILHO, O. B. Um modelo de zoneamento morfológico-funcional do espaço intra-urbano das cidades médias de Minas Gerais. in: AMORIM FILHO, O. B.; SENA FILHO, N. (Org.). A morfologia das Cidades médias. Goiânia: Ed. Vieira, 2005. p. 17-68.

CORRÊA, R. L. A rede urbana. São Paulo: Editora Ática, 1994. 96 p.

Trajetórias geográficas. Rio de Janeiro: Bertrand Brasil, 2010. 304 p.

FERREIRA, L. C. G; DEUS, J. B. Características da produção sucroalcooleira da microrregião de Ceres-GO: um abordagem sobre as políticas, a safra e a obtenção de terras. Ateliê Geográfico, Goiânia, v.5, n. 13, p. 196-218, mar.2011.

FRESCA, T. M. Rede urbana e divisão territorial do trabalho. Geografia, Londrina, v. 19, n. 2, p 115-128, 2010.

GOIÁS. Secretária de Gestão e Planejamento do Estado de Goiás. Regiões de Planejamento: 2011. Goiânia: SEGPLAN, 2012. 237 p.

GOMES, P.C.C. Um lugar para a Geografia: contra o simples, o banal e o doutrinário. In: MENDONÇA, F.; LOWEN-SAHR, C. L.; SILVA, M. da (org.). Espaço e Tempo: complexidades e desafios do pensar e do fazer geográfico. Curitiba: ADEMADAN, 2009. p 13-30.

HAESBAERT , R. O mito da desterritorialização: do "fim dos territórios" à multiterritorialidade. Rio de Janeiro: Bertrand Brasil, 2004. 400 p.

IBGE. Instituto Brasileiro de Geografia e Estatística. Censo Demográfico 2010. Rio de Janeiro, 2011.

IBGE. Instituto Brasileiro de Geografia e Estatística. Enciclopédia dos Municípios Brasileiros. Rio de Janeiro, 1958. 
IBGE. Instituto Brasileiro de Geografia e Estatística. Regiões de Influência das Cidades: 2007. Rio de Janeiro, 2008.

PAULA, M.C; SILVA, C.M; CORDEIRO, F. H. Impactos das políticas públicas e a importância da Cooper-Rubi no desenvolvimento de Rubiataba no Estado de Goiás. Estudos, Goiânia, v.34, n.9/10, p. 735-764, set./out. 2007.

SOUZA, M. J. L. ABC do desenvolvimento urbano. Rio de Janeiro: Bertrand Brasil, 2010. $192 \mathrm{p}$.

\section{Leonardo de Castro Araújo}

Mestrando pelo Programa de Pós-Graduação em Geografia do Instituto de Estudos Sócio-Ambientais da Universidade Federal de Goiás.

Campus II, Cx. Postal 131, CEP 74001-970, Goiânia - GO, Brasil

Leo.dcastro.geo@gmail.com

Recebido para publicação em setembro de 2012

Aprovado para publicação em abril de 2013 